\title{
Electromagnetic Interference Shielding Characteristics of Sn-Al Powder Coating Layers
}

\author{
Fei-Shuo Hung ${ }^{1}$, Fei-Yi Hung ${ }^{2, *}$, Che-Ming Chiang ${ }^{1}$ and Truan-Sheng Lui ${ }^{3, *}$ \\ ${ }^{1}$ Department of Architecture, National Cheng Kung University, Tainan, Taiwan 701, R. O. China \\ ${ }^{2}$ Institute of Nanotechnology and Microsystems Engineering, Center for Micro/Nano Science and Technology, \\ National Cheng Kung University, Tainan, Taiwan 701, R. O. China \\ ${ }^{3}$ Department of Materials Science and Engineering, National Cheng Kung University, Tainan, Taiwan 701, R. O. China
}

Sn-xAl powder complex materials are used as coating in building materials. This study coats complex colloid mixed with Sn-xAl powders and polyethylene on glass to examine the shield effect on electromagnetic interference (EMI). The results show that adding Al to the Sn-xAl powders can increase the electromagnetic interference (EMI) shield at lower frequencies. Notably, the number of cavities in the coating layer increased with the coating thickness, with the result that the EMI shield could not improve with an increase in the coating thickness at higher frequencies. [doi:10.2320/matertrans.MER2007252]

(Received October 25, 2007; Accepted January 9, 2008; Published February 25, 2008)

Keywords: electromagnetic interference (EMI), Sn-Al, building materials

\section{Introduction}

In recent years, some research in epidemiology journals has found that people who have been exposed to a high electromagnetic environment for a long duration become more susceptible to leukemia and brain tumors. ${ }^{1,2)}$ In addition, Bioelectrochemistry journal indicated, ${ }^{3)}$ that electromagnetic waves of over $60 \mathrm{~Hz}$ will cause damage and variations to the human body's DNA structure. Relevant literature has shown that people who are exposed to a high electromagnetic environment for a long duration become more susceptible to diseases than normal people. ${ }^{4-6)}$ Therefore, how to use building materials to improve the electromagnetic environment is not only a very important issue, but also conforms with the objective of green architecture. ${ }^{7)}$

Electromagnetic interference (EMI) is a new form of pollution discovered in recent years. ${ }^{8-12)}$ As of now, many laboratories investigate the technology of electromagnetic interference (EMI) shielding. Some surface technologies possess better EMI shielding, including conductive films ${ }^{13-21)}$ and mixed conductive powders. ${ }^{22-27)}$ Problems such as wear, peeling, oxidation, hard-working and expensive cost have resulted in the applied capacity of building materials to decrease. However Sn and Al not only possess EMI shield efficiency, but also have acceptable costs ${ }^{28)}$ and can be used to make Sn-xAl powders through a simple process, after which the Sn-xAl powders are mixed with polyethylene to perform the coatings. This study uses Sn-XAl coatings mixed with polyethylene not only to analyze the characteristics of the powders, but also investigate the effects of differing $\mathrm{Al}$ content and thicknesses of the EMI shielding so as to further understand the potential for use as a building material.

\section{Experimental Method}

\subsection{Synthetic complex paste}

This study selected three kinds of Sn-xAl $(x=20,30$,

*Corresponding author,

E-mail: fyhung@mail.mse.ncku.edu.tw,z7408020@email.ncku.edu.tw
40 mass \%) powders to perform the EMI shielding experiment. The particle size of the irregular Sn-xAl powders was in the range of $10 \mu \mathrm{m}-60 \mu \mathrm{m}$. The polyethylene $(x=20,25$, 30 mass\%) was mixed into the Sn-xAl powders to form a complex paste (Sn-xAl and polyethylene). Next, the paste was coated onto a glass plate of dimensions $20 \mathrm{~cm} \times$ $15 \mathrm{~cm} \times 2 \mathrm{~cm}$. After scraping-form ${ }^{29)}$ and solidification treatment at room temperature for 72 hours, a rectangular coating film of $20 \mathrm{~cm} \times 15 \mathrm{~cm}$ was obtained. After coated, the microstructures of the coatings were determined quantitatively using a X-ray diffraction (XRD). The $\mathrm{Cu}-\mathrm{K} \alpha$ standard $(\lambda=1.5403 \mathrm{~nm})$ was used and the scanning angle was varied from $20^{\circ}$ to $100^{\circ}$ and the scanning velocity was $1^{\circ} \cdot \mathrm{min}^{-1}$.

In addition, the number of coating layers was varied from 1-layer, 2-layers and 3-layers (hereafter referred to as $\mathrm{x}-\mathrm{L}$ ). The thickness of each coating layer was in the range of $50 \pm 10 \mu \mathrm{m}$. In order to understand the difference in characteristics of the powders and the coating layers, the structures of the affected regions were examined using a scanning electron microscope (SEM) to clarify the electromagnetic shield effect of the present $\mathrm{Sn-xAl}$ powder systems.

\subsection{Electromagnetic interference shield test}

The Elgal set 19A coaxial holder was used for electromagnetic interference shield testing. The range of scan frequency is from $300 \mathrm{k}$ to $3 \mathrm{GHz}$, and its accuracy is $\pm 10 \mathrm{ppm}\left(25^{\circ} \pm 5^{\circ}\right)$. A plane wave was used for vertical firing. The frequency range was controlled from $50 \mathrm{MHz}$ to $3 \mathrm{GHz}$. Each datum was the average of at least 3-7 test results.

\section{Results and Discussion}

The appearance of the Sn-xAl powders is shown in Fig. 1. We found that the Sn-20Al powders (Fig. 1(a)) and the Sn30Al powders (Fig. 1(b)) were similar in shape. The size of both particle-like powders were in the range of $10 \mu \mathrm{m}-40 \mu \mathrm{m}$. However, the brittleness of the $\mathrm{Sn}-\mathrm{xAl}$ powders increased as the $\mathrm{Al}$ content was raised, resulting in the shape of the $\mathrm{Sn}$ $40 \mathrm{Al}$ powders showing a whisker-like, not a particle-like 


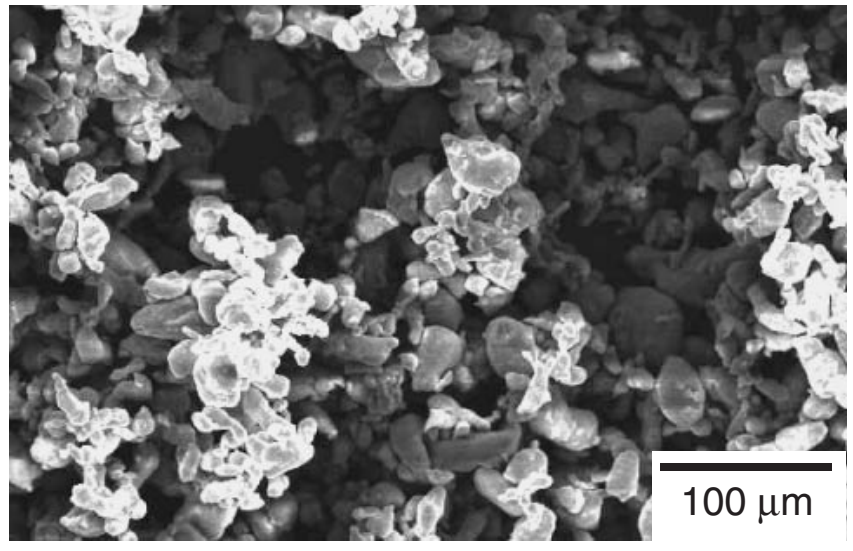

(a)

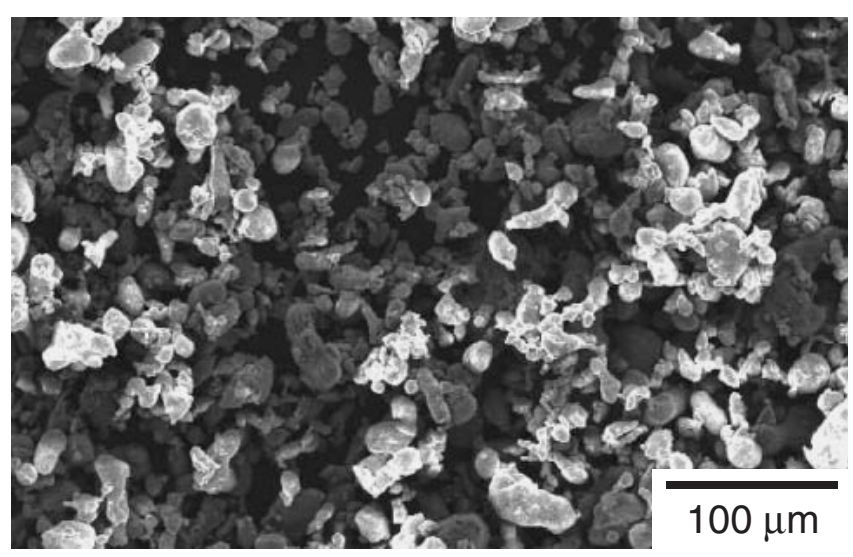

(b)

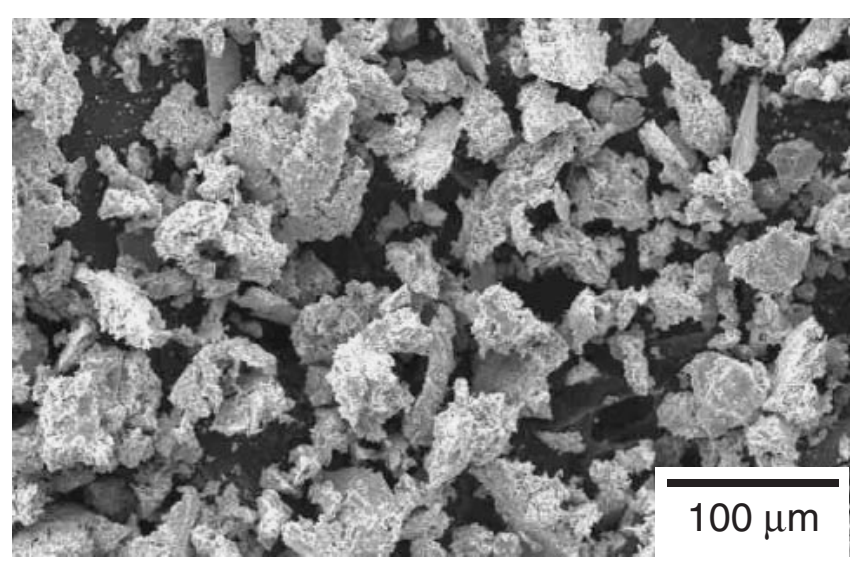

(c)

Fig. 1 SEM of Sn-xAl powders: (a) Sn-20Al (b) Sn-30Al (c) Sn-40Al.

(Fig. 1(c)) appearance and the whisker size was around 20$60 \mu \mathrm{m}$. So, the particle size of the present powders was selected to be $30 \pm 10 \mu \mathrm{m}$. Notably, the structure of the Sn$40 \mathrm{Al}$ powder was looser than that of the other Sn-xAl powders. In fact, the particle size of the Sn-40Al powder was the finest after a distribution process.

In our previous studies, we used $\mathrm{Sn}-\mathrm{xAl}$ powders mixed with polyethylene 25 mass $\%$ to form a paste of suitable viscosity. In the present study, the content of the polyethylene was controlled at 25 mass $\%$ for mixing with the powders. The pastes were mixed for $1 \mathrm{~min}$, then coated 1-3 layers on a glass plate. Hereafter, the specimens will be designated

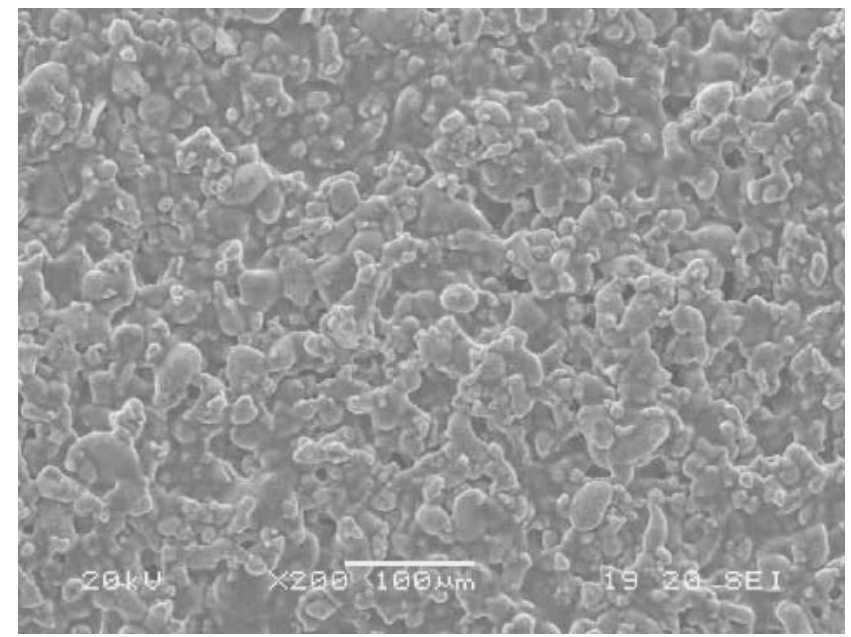

(a)

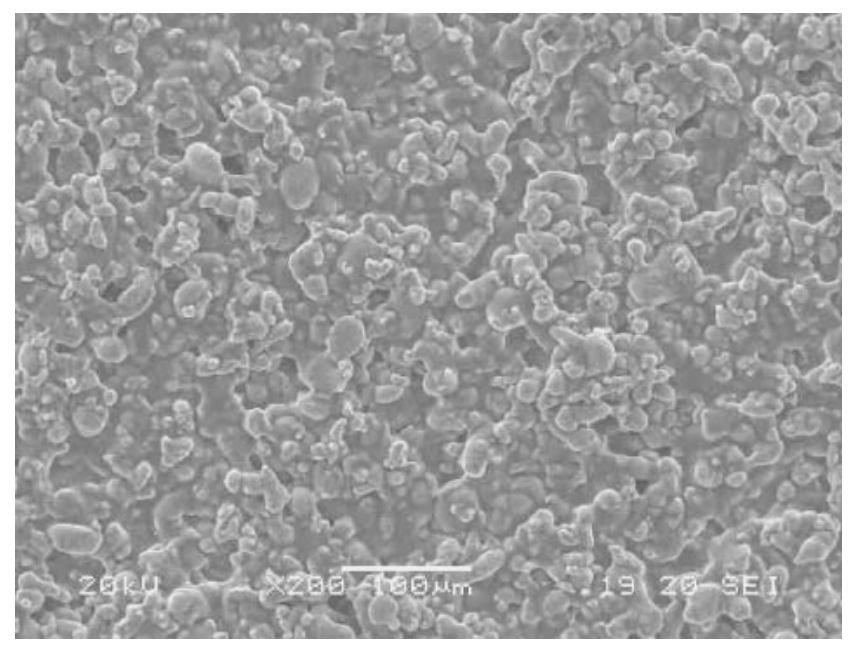

(b)

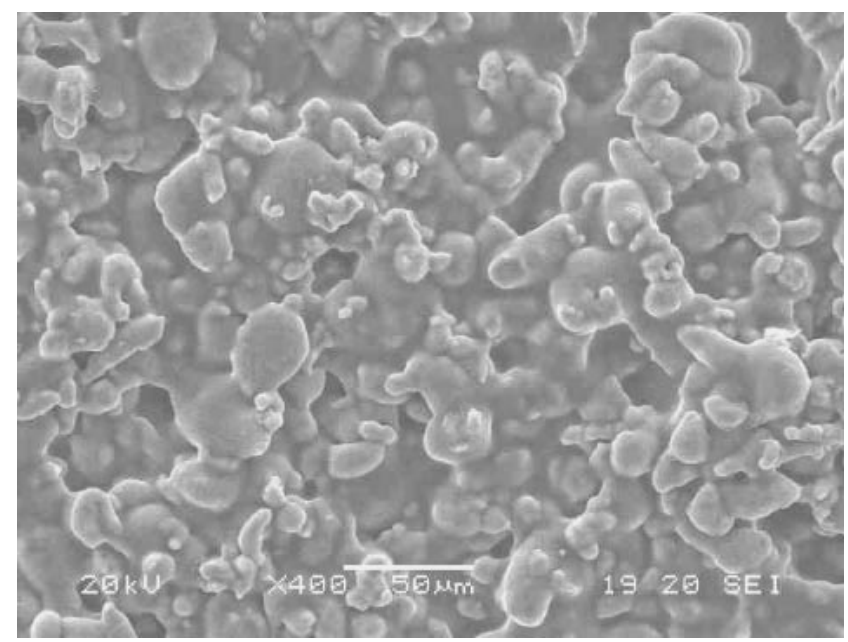

(c)

Fig. 2 Surface characteristics of coating: (a) Sn-20Al-1L (b) Sn-40Al-1L (c) $\mathrm{Sn}-40 \mathrm{Al}-3 \mathrm{~L}$

according to the no. of layers as $\mathrm{x}-\mathrm{L}, x=1,2$ and 3 . The thickness of every coating layer was around $50 \pm 10 \mu \mathrm{m}$. The multi-coating substrates were solidified at room temperature for $72 \mathrm{hrs}$, after which structural observation and EMI shield testing were performed. 


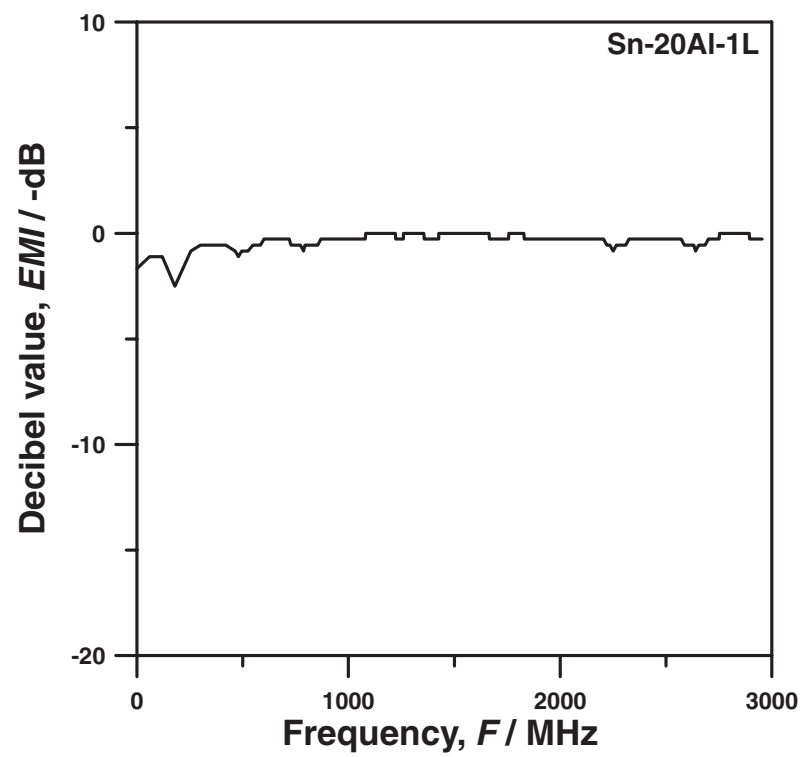

(a)

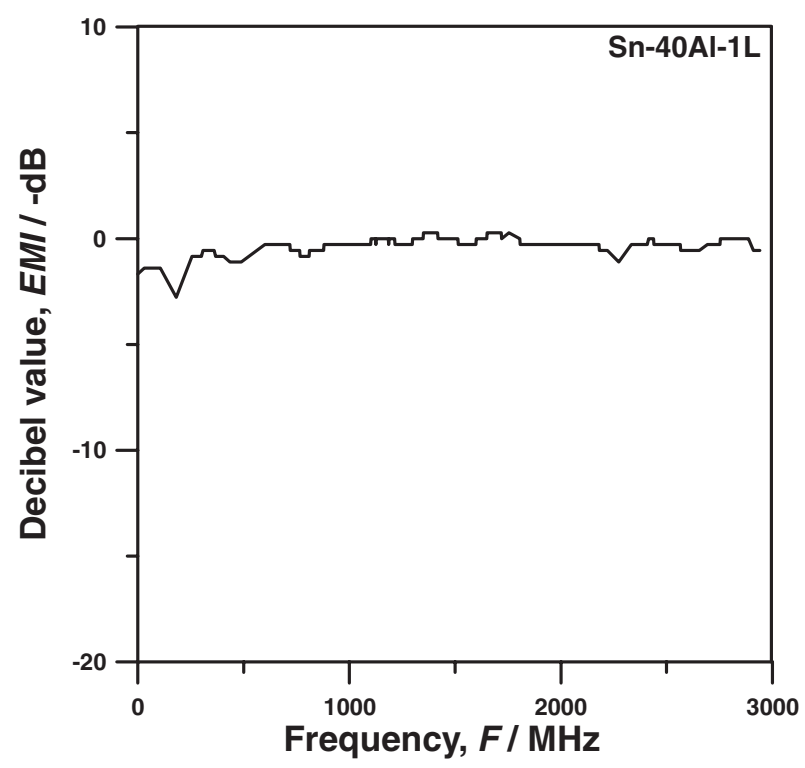

(b)

Fig. 3 Single layer coating of Sn-xAl: (a) Sn-20Al-1L (b) Sn-40Al-1L.

Table 1 The average $\mathrm{dB}$ value of coatings at different frequency.

\begin{tabular}{lccrr}
\hline Specimen & $\begin{array}{c}300 \mathrm{MHz} \\
(\mathrm{dB})\end{array}$ & $\begin{array}{c}900 \mathrm{MHz} \\
(\mathrm{dB})\end{array}$ & $\begin{array}{c}1.80 \mathrm{GHz} \\
(\mathrm{dB})\end{array}$ & $\begin{array}{c}2.45 \mathrm{GHz} \\
(\mathrm{dB})\end{array}$ \\
\hline Sn-20Al-1L & -0.9366 & -0.4622 & 0.1046 & -0.2218 \\
\hline Sn-20Al-2L & -8.8934 & -12.5428 & -13.8212 & -19.7326 \\
\hline Sn-20Al-3L & -11.2674 & -17.3312 & -17.0006 & -15.3534 \\
\hline Sn-40Al-1L & -1.0252 & -0.5181 & 0.0354 & -0.2128 \\
\hline Sn-40Al-2L & -9.3764 & -16.7716 & -13.5900 & -18.4596 \\
\hline Sn-40Al-3L & -12.3566 & -14.7066 & -12.3312 & -15.1082 \\
\hline
\end{tabular}

Figure 2 shows the surface characteristics of the $\mathrm{Sn}-\mathrm{xAl}$ coatings. Comparing Fig. 2(a) with Fig. 2(b), no obvious difference is found on the surface of a single coating. Although the particle size of the Sn-40Al powder with a loose

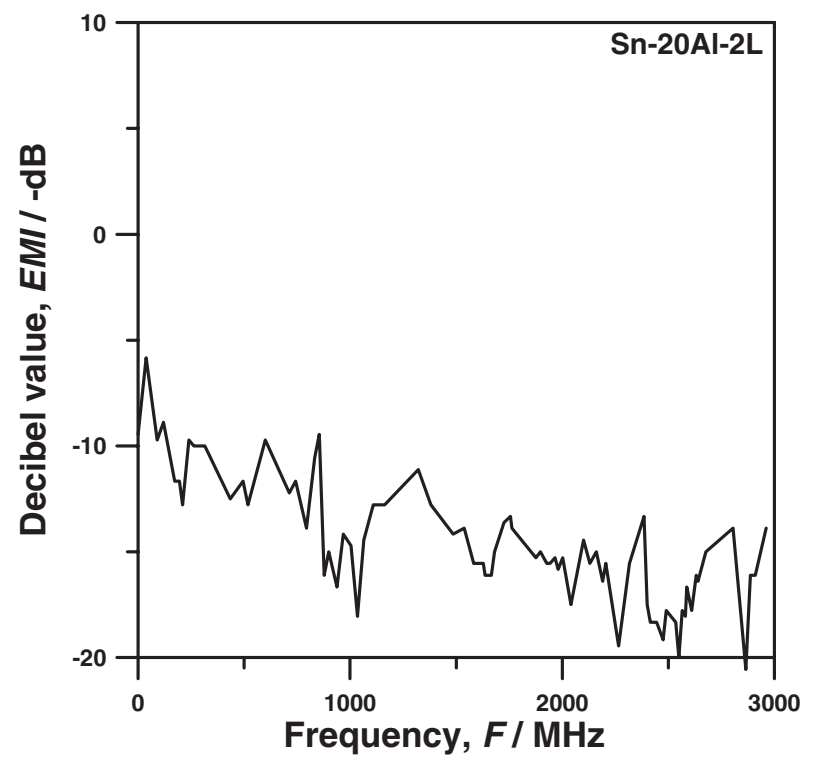

(a)

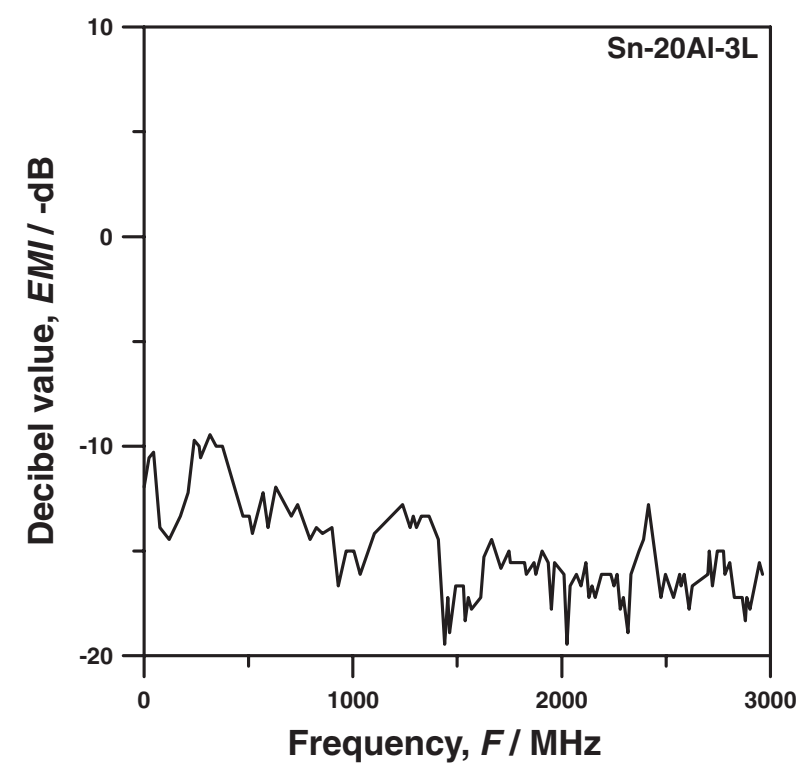

(b)

Fig. 4 Multi-layer coating of Sn-20Al powders: (a) 2L (b) 3L.

structure is larger, the mixing process had a dispersing effect which refined the structure of the solidification coating layer. This effect also reduced the roughness of the coating surface. For the 3-layer coating substrate, the surface characteristic was similar to the 1-layer coating substrate (Fig. 2(c) is a magnifying observation). Notably, the roughness of the coating surface had a tendency to increase as the number of coating layers increased.

Figure 3 shows the EMI shielding data of Sn-xAl with a single coating layer. The experimental frequency range was from $50 \mathrm{MHz}-3 \mathrm{GHz}$, and the decibel $(\mathrm{dB})$ value at four fixed point frequencies $(300 \mathrm{MHz}, 900 \mathrm{MHz}, 1.8 \mathrm{GHz}$ and 2.45 $\mathrm{GHz}$, as shown in Table 1) were recorded to analyze the EMI shield efficiency. Regardless of the Al content in the Sn-xAl powders (Fig. 3), the single coating had no EMI shield effect. Notably, when the number of coating layers was increased 


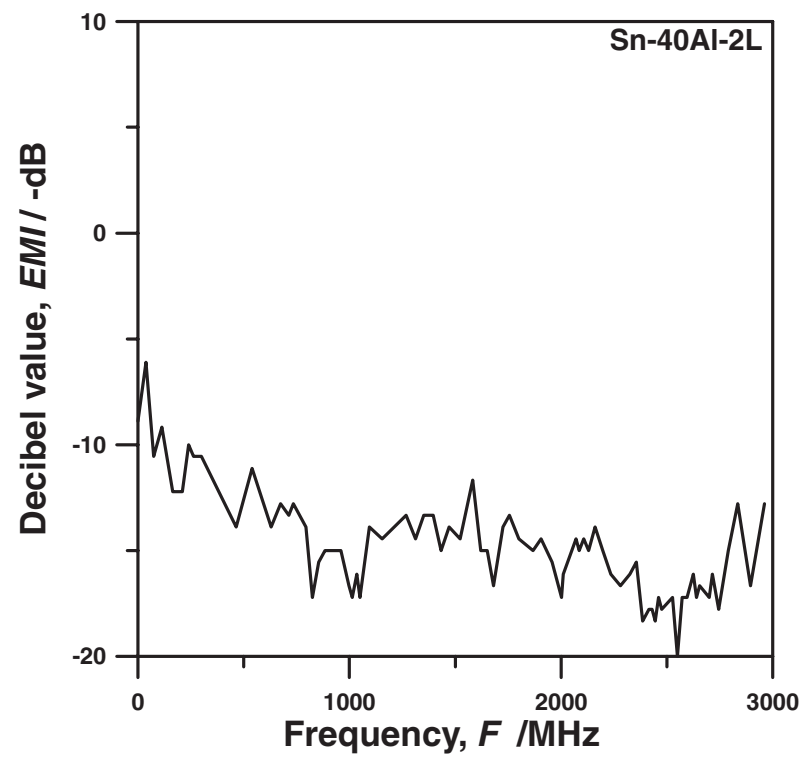

(a)

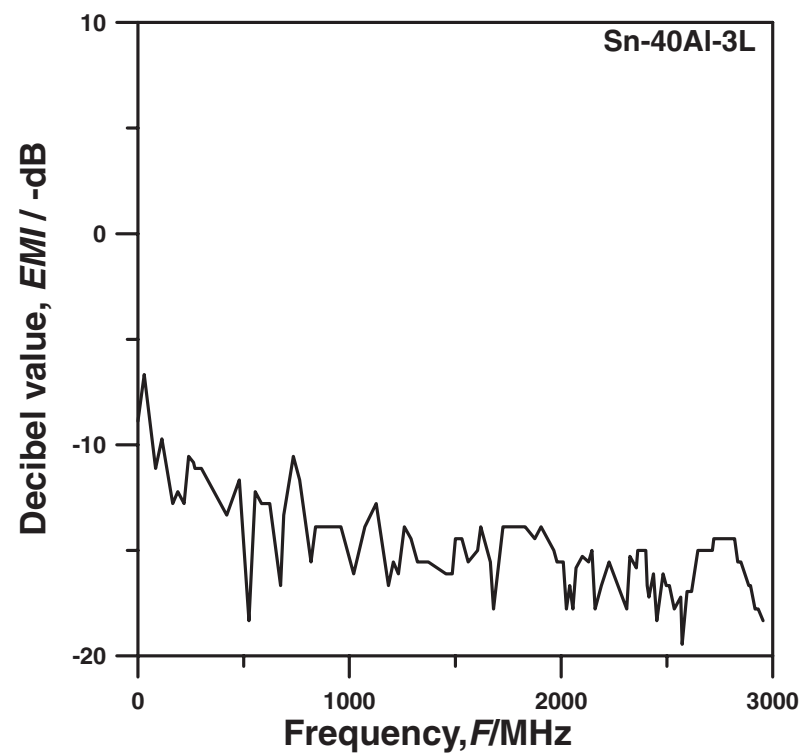

(b)

Fig. 5 Multi-layer coating of Sn-40Al powders: (a) 2L (b) $3 \mathrm{~L}$.

from 1 to 2 (Fig. 4(a)), there was an obvious effect on the EMI shielding (Fig. 3(a) and Fig. 4(a)). In addition, the EMI shielding at high frequencies was better than at low frequencies. The EMI shielding data of the 3-layer Sn-20Al coating is shown in Fig. 4(b). Except for $1.8 \mathrm{GHz}$ and $2.45 \mathrm{GHz}$ (see Table 1), the EMI shielding of the 3-layer coating was better than the 2-layer coating. Therefore, it can be seen that the EMI shielding effect is not certain to increase as the thickness of the coating layer increases at high frequency conditions $(\geq 2.45 \mathrm{GHz}$ ). The same result was also found in the multi-Sn-40Al coatings (Fig. 5 and Table 1).

Figure 5(a) shows the EMI shielding data for the 2-layer Sn-40Al coating, while the 3-layer coating is shown in Fig. 5(b). If we compare Fig. 3-Fig. 5 and Table 1, we see that the 2-layer coating processed excellent EMI shielding for all present coatings. For the $\mathrm{Sn}-40 \mathrm{Al}$ coating, increasing the number of coating layers from 2 to 3 deteriorated the EMI

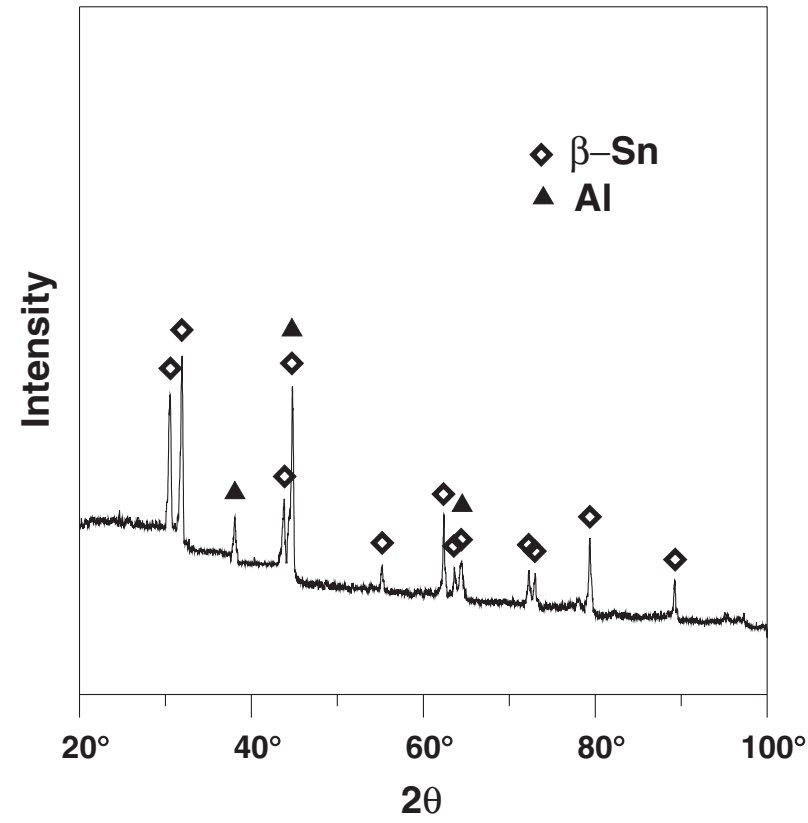

(a)

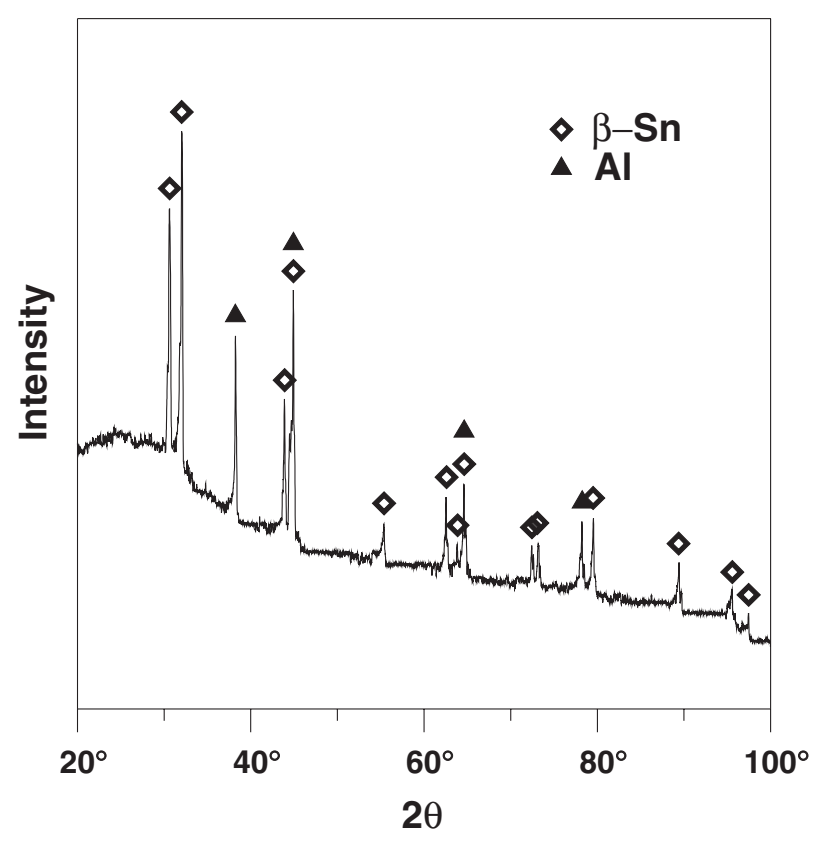

(b)

Fig. 6 XRD of Sn-Al coating layer: (a) Sn-20Al and (b) Sn-40Al.

shielding at frequencies of more than $900 \mathrm{MHz}$. Comparing Fig. 4(a) with Fig. 5(a) for identical 2-layer coatings, the EMI shielding of the Sn-40Al coating was higher than the Sn$20 \mathrm{Al}$ coating at low frequency testing. However, this tendency was reversed at high frequencies (see Table 1). In other words, the Sn-40Al did not improve the EMI shielding at high frequency conditions, even when the number of coating layers was increased. So, it is safe to say that the Al content of the Sn-xAl coatings affected the EMI shielding at different frequency conditions. At low frequencies, the high $\mathrm{Al}$ content coatings had excellent EMI shielding; the low Al content coatings possessed better EMI shielding at high frequencies. 

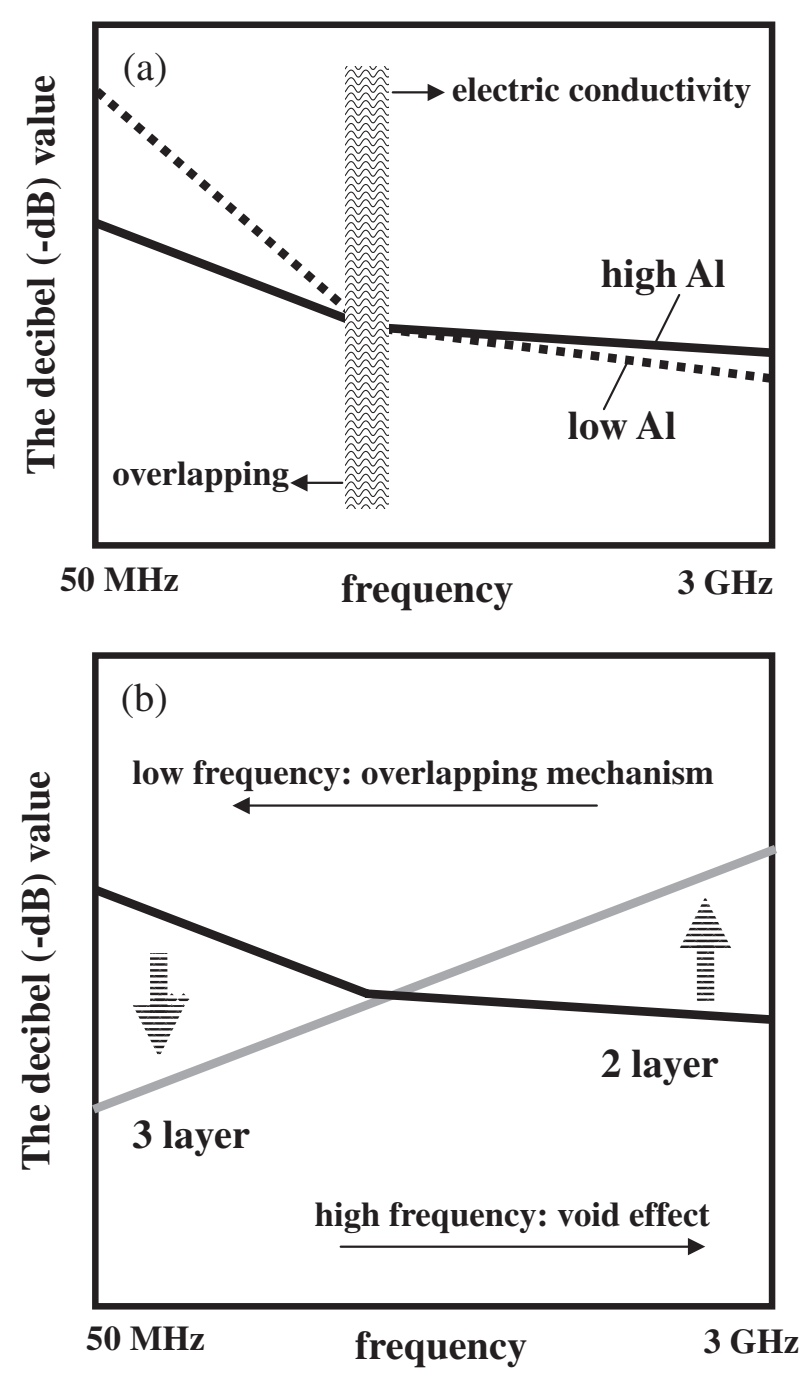

Fig. 7 EMI shielding characteristics of Sn-Al coating layer: (a) Al content effect and (b) the number of coating layer.

In order to understand the mechanism of EMI shielding, the X-ray diffraction (XRD) of the coatings and the electrical conductivity of the powders were measured. Figure 6 shows XRDs of the Sn-20Al-2L coating and Sn-40Al-2L coating. The results show that the microstructure of the Sn-20Al-2L coating is similar to that of the Sn-40Al-2L. The solid solution limit of Al was low in Sn matrix, and the Sn-Al precipitated phase not only affected the brittleness of the powders, but also induced a variation in an electric conductivity. These are 2 reasons why the $\mathrm{Al}$ content was closely related to the mechanism of EMI shielding.

Relevant literature, ${ }^{30)}$ as well as the present results, indicate that Sn-40Al undergoes a dispersing effect which forms a fine overlapping structure, thereby improving the low frequency EMI shielding. In addition, the Sn-20Al powders possessed the properties of a small particle size, closed structure and higher electric conductivity $\left(\sim 6.18 \times 10^{-5}(\Omega\right.$ $\mathrm{cm})$ ) which improved the high frequency EMI shielding (Fig. 7(a)). Take Sn-40Al coatings from 2-layers to 3-layers for example, the void content will get up $\sim 12$ vol. $\%$ (from 5.3 vol. $\%$ to 17.4 vol. \%) resulting in the electric conductivity to decrease. The most likely explanation for this is an increase in the thickness of the coating cannot improve the high frequency EMI shielding (Fig. 7(b)).

With respect to use as a building material, the high $\mathrm{Al}$ content coatings had excellent low frequency EMI shielding and acceptable cost. Furthermore, most environments have a low frequency electromagnetic field, so using the Sn-40Al coatings in the interface of building materials can promote the EMI shielding.

\section{Conclusion}

(1) The electric conductivity decreased as the Al content of the Sn-xAl coatings increased. However, the fine overlapping structure promoted the low frequency EMI shielding. For low Al coatings, the amount of Sn-Al compounds decreased which increased the electric conductivity and improved the high frequency EMI shielding.

(2) Because of an obvious polyethylene effect, the single layer coating had no EMI shielding effect. Due to a large number of voids, the EMI shielding of the multi-coated specimens deteriorated.

\section{Acknowledgements}

The authors are grateful to National Cheng Kung University, the Center for Micro/Nano Science and Technology (NCKU Project of Promoting Academic Excellence \& Developing World Class Research Center: D96-2700) and the Chinese National Science Council for its financial support (Contract: NSC 96-2221-E-006-103-MY2).

\section{REFERENCES}

1) C. Polk and E. Postow: Hand Book of Electromagnetic Fields, 2nd Ed., (CRC Press Inc., 1996) 212-213.

2) C. F. Blackman, J. P. Blanchard, S. G. Benane and D. E. House: J. FASEB 9 (1995) 547-551.

3) C. F. Blackman, S. G. Benane, J. R. Rabinowitj, D. E. House and W. T. Joines: Bioelectromagnetics 6 (1985) 327-338.

4) C. J. Merchant, D. C. Renew and J. Swanson: Journal of Radiological Protection 14 (1994) 77-87.

5) B. R. Mcleod and A. R. Liboff: Bioelectromagnetics 7 (1986) 177-189.

6) J. M. R. Delgado, J. Leaf, J. L. Monteagudo and M. G. Gracia: J. Anat. 134 (1982) 533-551.

7) C. M. Chiang and C. M. Lai: Building and Environment 37 (2001) 387392.

8) N. Day, J. Skinner, E. Roman and S. G. Allen: The Lancet 354 (1999) 1925-1931.

9) M. Fechting and A. Ahlbom: Am. J. Epidemiol. 138 (1993) 467-481.

10) V. Manni, A. Lisi, D. Pozzi, S. Rieti, A. Serafino, L. Giuliani and S. Grimaili: Bioelectromagnetics 23 (2002) 298-305.

11) J. Burnett and Y. Du: Seventh International IBPSA Conference: Building Simulation (2001) pp. 327-333.

12) T. S. Tenforde and W. T. Kaune: Health Phys. 53 (1987) 585-606.

13) N. Wertheimer and E. Leeper: Am. J. Epidemiol. 109 (1979) 273-284.

14) A. Ubeda, J. Leaf, M. A. Trillo and J. M. R. Delgado: J. Anat. 37 (1982) 513-536.

15) A. R. Liboff: J. Biolog. Phys. 13 (1985) 99-102.

16) D. C. Paine, T. Whitson, D. Janiac, R. Beresford and C. Yang: Journal of Applied Physics 85 (1999) 12-15.

17) D. Liu and D. Suqiao: Asia-Pacific Conference on Environmental Electromagnetics (2000) 326-332.

18) J. L. Vossen: Physics Thin Films 9 (1997) 1-71.

19) R. M. Gresham: Plating and Surface finishing, (1998) 63-69.

20) C. S. Zhang, Q. Q. Ni, S. Y. Fu and K. Kurshiki: Composites Science 
and Technology 67 (2007) 2793-2980.

21) T. Wang, G. Chen, C. Wu and D. Wu: Progress in Organic Coatings, 59 (2007) 101-105.

22) K. Wenderoth and J. Petermann: Polymer Composites 10 (1992) 52 56

23) W. W. Salisbury: Absorbent Body for Electromagnetic Waves: U.S. Patent no. 259994410 (1952).

24) R. L. Fante and M. T. McCormack: IEEE Trans. Antenna Propagation 36 (1998) 1443-1454.

25) J. C. Liu, S. S. Ho and S. S. Bor: IEEE Proceeding-H 140 (1993) 414 416
26) E. G. Han, E. A. Kim and K. W. Oh: Synthetic Metals 123 (2001) 469476.

27) G. E. White: Liquid crystalline polymer and multilayer polymer-based passive signal processing components for rf/wireless multi-band applications: U.S. Patent no. 20070085108 (2007).

28) http://www.matter-antimatter.com/periodic_table.htm.

29) F. Y. Hung, T. S. Lui and H. C. Liao: Applied Surface Science 253 (2007) 7443-7448.

30) C. T. Lin: production of PT/PZT/PLZT thin films, powders and laser direct write patterns, U.S. Patent no. 5188902 (1993). 